\title{
Anchoring Design in Rural Customs of Doing and Saying
}

\author{
Nicola J. Bidwell \\ James Cook University, Australia \& Centre for ICT4D, Cape Town, South Africa
}

\begin{abstract}
An increasing range of initiatives aim to enable rural communities in developing regions to generate their own, non-text based, digital content to share local stories, information and concerns. Video, photos and audio offer new resources for practices that give communities' a sense of identity and continuity and that members acquire in relationships with each other, their environment and history via speech, gesture, song, music, drama, ritual, skills or crafts. However, these contexts pose challenges for designing interactions within frameworks that have a heritage of text and indirect orality and which emphasize particular communication dynamics and structures. We seek to create new design directions based on insights into local ways of 'doing and saying' gained in interactions with people living under traditional law and custom in the Xhosa Kingdom of Pondoland, South Africa. This paper distils themes from an ethnography when the author lived according to local norms and constraints and cogenerated design activities, situated in the community's priorities, customary power relations and consensus-based practice. We reflect on communication in ordinary and extraordinary activities, and sociotechnical 'experiments' from using social networking websites to storytelling with blogs. We describe how indexicality dynamically shares context and entwines a person's identity with physical setting; and, how practices, such as prolonged discussion, diachronic repetition and synchronous utterance, build rapport, collective memory and cohesion. We propose that these practices inspire ways that local social structures can impact on activities to design systems of organization for information sharing, with occasional reference to our observations of other rural peoples in north Mozambique and north Australia.
\end{abstract}

Keywords: Rural, Africa, Localizing design, Identity, Ethnography.

\section{Introduction}

An increasing range of initiatives aim to enable rural communities in developing regions to generate their own, non-text based, digital content to share local stories, information and concerns. Video and photos, sometimes linked to audio, offer new resources for practices that bestow a sense of identity and continuity to communities or groups and that members acquire through relationships with each other and with their environment and history via speech, gesture, song, music, drama, ritual, skills or crafts. To realise the opportunities for expression and communication that media and platforms can bring rural people we need to respond to the ways that knowledge is 
created and recreated beyond the 'market' [3] of contemporary communication. Technologies, from Web 2.0, online social networks to SMS, emerge in a market of symbols, concepts and structural forms with a heritage in text and indirect orality, such as radio, television. This market affects all cultures to some extent, but in places with low technology ambiance, such as in rural Africa, a 'primary orality' [12] pervades. Transmitting oral and performed knowledge, directly, involves constantly recreating, accumulating and dividing it across a group according to social systems and protocols and power relations. This intangible [18] stuff poses a challenge for designers tackling oral and performed knowledge within their own culture let alone when crossing into social fields without the same provenance of text and indirect orality. Yet, finding hooks in such social fields to tether design directions determines not only technology's contribution to developing regions (ICT4D), cultural diversity and heritage, but also our own creativity.

In this paper I discuss insights into oral and performed information sharing gained as we sought to anchor new design endevours in a rural African village living under traditional law. Tethering design to users' view of collectivity is core to inventing tools for locally generated content but is not straight-forward; for instance, Indigenous people in America struggle to translate their meaning of collectivity into western interaction [10]. Many technologists use generalised models of cultural dispositions to tune their methods to local expectations and values, for example Hofstede's dimensions alert us to African cultural tendencies towards collectivism, rather than individualism, and acceptance of unequal power distributions (e.g. [19, 20]). But theories are not conduits into a social field as they do not depict how meanings are constituted, and transformed, by a specific community. To create vehicles for local content sharing in rural Africa we need to find anchor points in activities that organise information and respond to the ways collectivity is enacted in these practices.

Context carries the burden of meaning in communication [1] and determines semantics, whether people convey meaning by drawing on the intangible, the concrete or the abstract. Browning has explored ways that meaning in rural places is grounded, within a corpus of locational, temporal, historical and social contexts, by drawing on properties of indexicality [4]. Indexicality [4] provides actions and utterances with salience and, reflexively, augments context during interactions. For example, consider understanding the meaning of terrain burnt by fire to a leisure walker [4] a farmer or an Indigenous Elder whose Traditional Knowledge (TK) about fire maintains species diversity [2]. We 'handle' and interpret this typical Australian feature in ways that depend on context; thus, items, categories and relations gain significance in context and shape the market in which creativity emerges. This may contribute to dissonance when software created 'elsewhere' [15] is introduced. For instance, a Kuku-Thaypan Elder expressed regret that a GPS-based system, designed to assist persisting TK, did not support the indexical practices of 'walking country' in which physical locations entwine with communication protocols, ancient stories and ritual [2]. Social practice tends to emerge from practical, rather than cognitive, concurrence and people are mostly unaware of the actions and interactions that yield meaning through indexical processes. The roles of items, categories and relations in interactions, between people or between a person and artifacts, evolve and gain significance tacitly, such that their 
potency is sanctioned by the success of the interaction. Indexical processes lay at the heart of approaches that ethnographers use to negotiate meaning, depict another's reality and explain practices in inaccessible contexts to designers.

Interaction is not a static set of norms and techniques but is situated in prior occasions, the immediate moment and a relational totality [4] via regulated improvisation. Our cultural habituation enables us to participate in daily activities and social interactions competently and contingently and also to act strategically and creatively. The more adeptly we improvise in social interactions the more power we have in their market; thus designers often leverage local social competence in ICT4D as a conduit for engaging people in the dialectic processes of design. The social power of 'seniorlevel champions' [9] and 'Human Access Points' [12] can help to domesticate an introduced technology but may also limit creativity to their particular indexical emphases and the scope of technology that they can envisage

We seek to create new design directions based on ways of 'doing and saying' and local needs in a remote, impoverished and technologically marginalized village in the Eastern Cape of South Africa. I situated research in the customary power structures and everyday practices that organise information in a social field dominated by primary orality, by residing in the patrilineal kinship group of a Headman. I start by introducing the setting and our approach to collecting data and, then, outline activities and interactions in, around and about the village of Lwandile in which I gained insights into priorities and oral and performed practices. I conclude by proposing that the ways these practices express collectivity is relevant to designing technologies for information sharing, with occasional reference to observations of Indigenous people in Quirimbas Archipelago, north Mozambique and north Australia.

\section{Situated in the Village of Lwandile}

The village of Lwandile is the home of 72 year-old Hlathinkhulu Sithelo who is the senior of twelve Headman with authority over 20, 000 people dispersed across $50 \mathrm{~km} 2$ of Lower Ndungunyeni. This area was settled at least eight generations ago by the Khonjwayo, one of six Chiefdoms descending from the monarchy of a distinct Xhosa tribal cluster in the Kingdom of Western Pondoland. Chiefdoms are territorial not pure kinship, thus the Khonjwayo share many kin but their ancestry also includes indigenous Khoikhoi and San, shipwrecked Europeans and exiles of the Apartheid era. Due to topology, local resistance to colonists, famine and invasion and subsequent neglect by successive regimes Ndungunyeni remains distinct and preserves traditions in habitation and communal landuse. Families live in umzi, informally distributed across hilly common grazing land and interconnected by paths to water. An umzi houses 4-5 adults and 2-7 children in cluster of thatched, mud-brick rondavels fronted by a garden and fenced kraal for livestock (Fig. 1b). With little paid employment locally many villagers temporarily migrate to cities so that, except at holidays, half of Lwandile's permanent population is under 15 years and women or pensioners head households. Even with remittances from emigrants and pensions most families survive on less that $10 \%$ of the national, median income for a working white man, although $\mathrm{H}$. Sithelo receives a government salary of $\$ 250$ per month which is in the 
top $10 \%$ of incomes in Lwandile. Traditionally a cattle culture, these days most families own a few of a range of animals and subsistence farm arable land for crops (e.g. maize). Rondavals last 40 years and most permanent built infrastructure reflects the Headsman's influence, such as a church built decade ago behind his umzi and a rocky, ungraded road to his umzi cleared by the municipality and along which the clinic was built. A few umzis, including the Headman's, have a solar panel but none have a mains water supply or grid electricity and solar power serves the clinic and, until the battery was stolen, the school as well.

\subsection{Data Collection and Analysis}

My analysis draws on ethnography in events that arose as I interacted with the setting and attempted to live according to local norms in situ. By residing in H. Sithelo's umzi and using only local, shared transport I was exposed to the geographic isolation of rural life and constraints on technology use (e.g. the limits of solar generated electricity to charge a deep cycle battery). I was also afforded social access and security due to the affectionate respect $\mathrm{H}$. Sithelo, who is known locally as 'Tata' (father) commands. As a foreigner and the only white woman in a wide area, I would have been vulnerable to local psychopathologies, related to HIV and alcohol and, allegedly non-local, bands of criminals. I recorded data using handwritten notes, 650 photographs, of which villagers took 200 and 12 hours of video, though digital recording was limited by electricity. I transcribed video, compiled 'thick' textual descriptions and iteratively integrated all records to derive themes hermeneutically. Unlike classic ethnography, which gathers qualitative data without targeted intervention, I aimed to co-generate a design approach by interpreting priorities and discovering opportunities for design in the ad-hoc details in daily life and by establishing relationships and undertaking 'sociotechnical experiments' [19]. Thus, here I depict my progression in the social field as four phases of activities and interactions, written in the first person to distinguish various actors and reflexivity.

\subsection{Phase 1: Deriving A Research Rationale}

I was introduced to Lwandile by Arjan, a Dutch volunteer in a Non-governmental organisation (NGO) who had championed a university technology project to link Lwandile clinic to Canzibe hospital [17]. While the remote healthcare system had not been a success he hoped the Wi-Fi bridge could be used to communicate with the "outside world" about foreigners' exploitation of the land and community. So he approached Thulani, the Headman's eldest son, who had bought the first cell phone to Lwandile in 2003, had recently sent his first email using a Nokia E60i Smartphone, donated by the university and was eager to host me on his father's umzi. I visited twice before moving in, first to be formally presented and gain insights into priorities and later to bring equipment to put in a room the Sithelos had furnished for me. In discussion with design collaborators I based a research rationale on initial observations and Thulani's interest in using technology to attract attention and funds for social upliftment initiatives. Thus, I sought to gather data on ways local leaders interface with the community and local and remote agencies on development projects. 


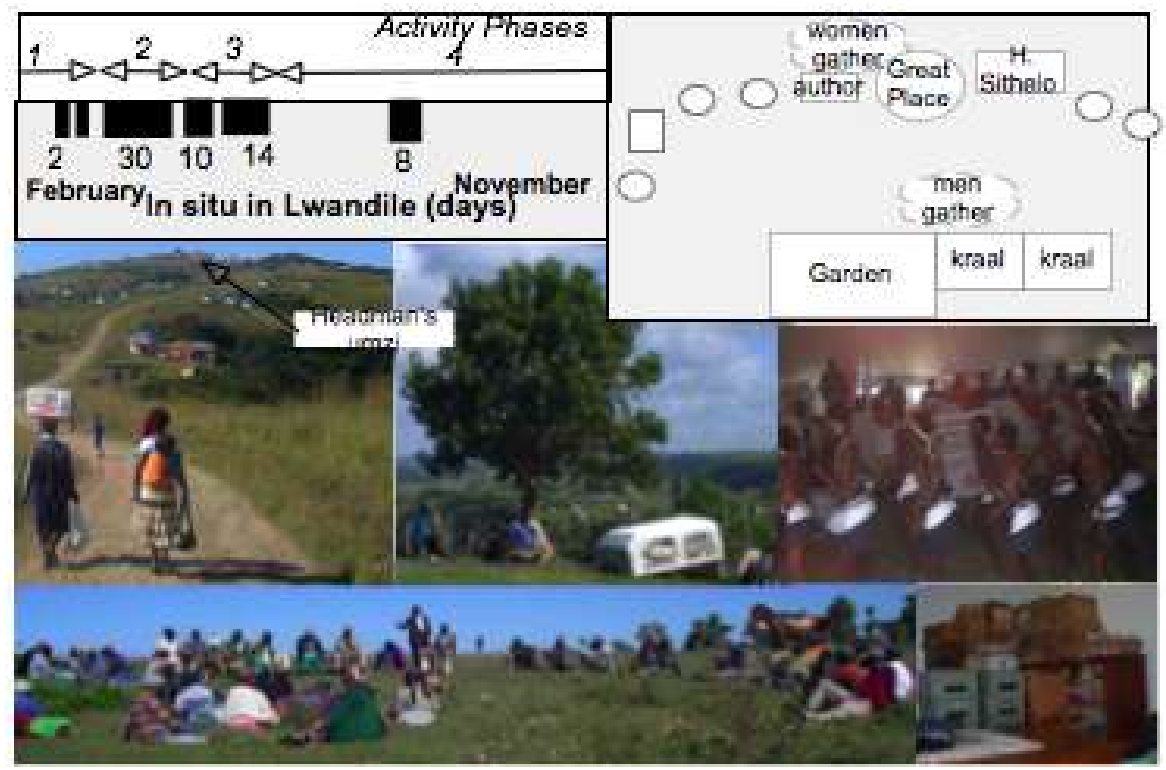

Fig. 1. Phases of activities (a) Layout of umzi (b) Road to H. Sithelo's umzi at top of hill (c) Men gather under the meeting tree (d) Dancers and dignitaries (taken by Sixolile) (e) H. Sithelo gestures at the meeting at Mngciebe (f) Palace Archives (g)

\subsection{Phase 2: Acclimatizing to the Social Field}

The first extended in situ phase lasted a month (Fig. 1) and most observation occurred around domestic and community life in H. Sithelo's umzi. The umzi comprises: the 'Great Place', used for community meetings; 6 other rondavals, formally used by male family members before they established their own umzi, and now used by visitors; a 4 room 'flat' (small square building) inhabited by H. Sithelo, his wife, youngest daughter Bulelwa, Bulelwa's infant, and two other grandchildren; and, a smaller flat where I lived in one room and the other room was occupied by various guests or the Sithelo's 20-year-old son when he was not at technical college. I gathered data through impromptu contextual interview while interacting with the family, in particular the elder sons, Thulani and Sixolile and participating in female duties (e.g. fetching water) and more passively observed villagers' visits to the umzi in connection with H. Sithelo's duties (e.g. resolving disputes, interfacing with police, signing permits for hunting and resources). I also recorded active events, such as walks to Sunday football matches, a meeting in the Great Place with the NGO's founder, a Transkei-raised Afrikaner (Johann), and walking through a forest near Mngciebe with Thulani and Johann as they discussed community projects.

In the first two weeks of Phase 2 (Fig 1a) I also undertook technology 'experiments' with Thulani and adjusted infrastructure. We moved the wireless router from its unused position in H. Sithelo's flat to my room and I introduced Thulani to various Internet facilities such as searching for information related to his interests, social networking (e.g. Facebook) and using photos to tell stories. I created a blog, www.topository.org, 
and uploaded a photo and Thulani enthusiastically received a digital camera and a laptop, to type text to accompany his photos. I also demonstrated the Internet to children, residents and visitors to the umzi who visited my room through curiosity, on errands or to charge cell-phones. In the first week Thulani said he needed to mobilize a Community Trust, comprising headmen from four villages, to advance his initiatives and decisively identified development projects on which to focus our activities. These related to using land near Mngciebe for agricultural food production and training and tourism and using technology to request funds (e.g. a blog to interest people overseas seeking to sponsor local initiatives).

We had preliminary success in oral storytelling around Thulani's photos of his daily life but, after a week, he lost interest in technology activities. He often forgot to bring the camera, did not type anything at his home, mentioning being unable to charge the laptop, and seemed bored when we used the Internet in other ways that I related to his development projects. He more eagerly discussed his beliefs about raising and using overseas funding, his plans and ability to marshal local support, his life and his culture. After the first two weeks there were 9 days when Thulani did not visit, appear at scheduled meetings, respond to SMS messages or organize activities we planned. I had scheduled time away at the end of a month in Lwandile and raised concerns with Thulani about lack of insight into the ways leadership interfaces with each other and local people on development projects. Thulani noted that mobilizing the Trust was slow as many members were old and inactive so I asked whether involving other villagers in technology activities would be advisable and Thulani agreed to ask his sister, Bulelwa, to act his secretary. This critical reflection relieved tension and Thulani accompanied me on the long trip to the bus and regularly contacted me in the week that I was away.

\subsection{Phase 3: Looking for Anchor Points}

A second in situ phase lasted one month, split midway when the Sithelos left the village to attend a funeral. It commenced with a transition in familiarity that led to my deeper involvement in Thulani's efforts which significantly expanded the dataset and refined the project's future. Diverse everyday data in Lwandile included impromptu discussions in the spaza, walks with various members of the Sithelo's extended family encountered in the village and sporadic visits to my room by local teenagers and people on business in the umzi, such as villagers, Lwandile's local Councilor and Thulani's brother-in- law, a Chief of another district. Further afield, I spoke to local people in tourist areas and white NGO volunteers in HIV awareness and ICT. Participant driven activities also became richer and began as soon as I returned and Thulani clarified his priorities by revealing that his aims for various local initiatives included pursuing the Sithelo's right to the Chieftainship. Thulani explained that 5 generations ago ancestors of the incumbent Chief had gained Chieftainship when the British deposed his Great Great Great Grandfather. This disempowerment led to local apathy, such as the Trust's inertia, and Thulani said that the Headmen under H. Sithelo's authority were "crying for dignity", which he sought to restore by lodging a claim, with the monarchy, for Khonjwayo Chieftainship. Meanwhile, to advance development projects he would mobilize activists related to the Trust. Shortly after the Chieftainship discussion Thulani and I traversed forested and rocky hills to visit Johann at 
Mdumbi, accompanied Thulani and H. Sithelo, on horseback, to a hill-top community meeting in Mngciebe and a school's official opening. I also joined Thulani in the Great Place for meetings with younger activists in the Trust (35 to 39 years) who decided to form an independent non-profit organization: The Federation of Rural Coastal Communities (FRCC). The four men of the FRCC include Thulani; Mfundiso, a sub-Headsman's son and a teacher; Bongile, a teacher; and, Xolile who also Chairs another grassroots association. Further, afield I went with Thulani to consult Mthatha Municipal Archives and accompanied Thulani and H. Sithelo to the Palace to search for records, meet the Queen and attend a meeting.

Greater involvement in activities relating to Thulani's priorities increased opportunities to situate technology 'experiments'. From early in Phase 3 I embarked upon 15 'tutorials' with Bulelwa, who had a certificate in MS Word and Excel, which she had achieved without using a computer. Bulelwa, with her swaddled infant bound to her back, spent about an hour a day in my room learning to set-up solar power, explore the Internet for information of interest to her and send emails (e.g. to enquire about support for university study on social work). Meanwhile, Thulani and I discussed how the Internet might help in researching ancestry and emailed a contact in The National Archives \& Records Services (NARS). Matome at NARS replied with suggestions on finding records and the possibility of bringing his department's new outreach program, 'Taking the Archives to the People', to Lwandile. The newly formed FRCC decided this was a rare opportunity to bring useful information to the community and discussed including it within an event on cultural and natural heritage, development and oral traditions. Email exchanges, related to research on Thulani's lineage and to the event, and a donation in response to a comment on my Facebook 'status update', to pay for fuel for a generator, illustrated the relevancy of ICT. The FRCC had reservations about technology until Thulani demonstrated using his E60i and raised ideas about business models to fund mobile communications.

With better insight into the relations between ancestry and development we cogenerated activities to accumulate data on 'digital storytelling'. Bulelwa used a donated camera and uploaded records of 'Life in Lwandile' to the blog and Sixolile used the camera at a three-day party to honour the Queen. I videoed Sixolile viewing and describing his photos on the laptop, and he used the two media with great expression, the next day returning with a newspaper article about the party to further explain customary law. I also videoed Sixolile in walks crisscrossing Lwandile and in an interview with H. Sithelo with Sixolile translating and observed more impromptu digital storytelling by Thulani when we attended the opening of a new school.

\subsection{Phase 4: Discovering Anchor Points}

The last phase of activity analysed here started when I left Lwandile at the end of Phase 3 for research in Mozambique (Fig 1). To begin with I communicated remotely while the FRCC coordinated hosting the NARS Outreach team and a workshop in Lwandile, contacted municipal authorities and fund-raised. While invited to influence the structure and program I withheld comments, other than in support, to gain insight into the FRCC's approach. Two months into Phase 4, I returned to Lwandile for 8 days to gather data before, during and after the workshop. The 3.5-day workshop was structured around seven spoken presentations by: NARS; The Provincial Departments 
of Land Affairs and Environment; The Provincial House of Traditional Leaders; an emissary of Chief Gwadiso; and, Rosette, the local elected Councilor. Presentations were interleaved with protracted debate on archiving, local history, natural and cultural heritage, natural resource management, sustainable development and legislation on collectively owned land. Sessions also included a group exercise, critique and requests for future events, extensive votes of thanks and a film: Sarafina!

Early in Phase 4, I also introduced Xolile and Thulani to an American researcher (S) who was consulting for an IT company and they met briefly in Mthatha which enabled them to raise funds to register the FRCC. S encouraged Thulani to take an interest in Facebook but he did not download the 'how to' S created for him; so on my return to Lwandile we set up an Facebook account and created a Group to serve the FRCC. We also spent an hour creating blog entries with Bulelwa who had uploaded new photos to the laptop. In planning the workshop and the meeting with $\mathrm{S}$, Xolile, the Secretary of FRCC, emailed or copied me into 24 emails to exchange information or seek advice. Wider communication was a persistent problem preventing the FRCC from creating a media draft, publicising the workshop as planned or co-ordinating transport. Hence, only $25 \%$ of their expected 200 to 300 participants attended. Thulani continued to use the lap-top but emailed me less regularly than Xolile, sending 9 emails before the workshop. Since the workshop, we set up email for Bongile, who has yet to use it, and Xolile presented a paper about the workshop at an oral history conference. I also received 11 messages and several invitations through Facebook, 18 emails from Thulani, Xolile and Bongiwe and have phoned Thulani and Sixolile. The FRCC's Facebook group (http://www.facebook.com/group.php? gid=35995351952) has 41 members, most of whom are Xhosa people connected through Bongwe, studying in Cape Town (35\%); collaborators (e.g. authors in this project and the NGO in Mdumbi) (23\%); and, 'friends' overseas introduced by S (27\%). There are equal proportions of Xhosa people and non-Xhosa, and most of the latter do not live in Africa.

\section{Reflections on Information Sharing}

The hooks, in Lwandile's social fields, to which we can tether new design directions for sharing local information in development initiatives emphasise orality and performance. My analysis here refines insights about these anchors as a step in focusing activities to involve villagers in designing technologies. A starting point is the rarity of ambient text and literacy in everyday information sharing; for example, there is only one road sign, 'Lwandile', few labeled food products or posters, no local postal service, few people have poste restante addresses, or books, and, with limited written materials in Lwandile and Mgneibe school, children often learn by rote. Up to half of 9 -year-olds cannot read, as many villagers speak only Xhosa but young children learn to read in English, and education is often truncated as less than $70 \%$ of those starting school at 7 years continue to 15 , often assuming family duties when orphaned or married. Observations of people casually interacting with text, such as scouring job advertisements in English language newspapers brought from Mthatha or graffiti on school desks, were seldom and most observations of literacy were domain-specific and accompanied by some formality. For instance, Mfundiso re-wrote attendance lists at every meeting until they were perfect and teenage girls taking notes at the 
workshop did so with care. History recorded in text seems uninteresting, for example a unique poster display of newspaper articles on Apartheid attracted little attention at the workshop and the archives in Mthatha and at Limbode castle do not appear organized or regularly consulted (Fig 1g). Social practice, and preferences for media when present (e.g. TV, radio), emphasize orality, song and dance. People often sing while tending gardens or life-stock and start each day with hymns, choral group is a regular activity and the rarity of electricity means that any event with an amplifier attracts people to dance informally or in performance (e.g. at the workshop, the school opening). Many villagers over 15 years own or share a cell-phone, which they prefer to use to speak than SMS but do so rarely as airtime is unaffordable and not easily purchased locally. Thus, to create design activities for the community we are cautious not to emulate methods for text-based literacy.

Orality in Lwandile reflects durable traditions and, perhaps, the interplay between oppression in South Africa, historically, and the hegemonic effects of Western literacy and media. In village life people are not stigmatized as illiterate and associate status and dignity with other attributes, such as being in a Gospel choir or wageearning (e.g. H. Sithelo ran away from school to work) but, as national speakers at the workshop reiterated, relying on orality is a disadvantage in modern, democratic and legislative South Africa. Villagers were stirred by NARS speakers' warnings that "No-one will know your history if you are not protecting". However, they perceive their obligation to preserving their heritage according to customs rather than by textbased recording. This suggests we need to attend to elements of these practices before re-purposing Western styles of recording for illiteracy or local language.

\subsection{Embodiment in Physical Settings Orients Information}

Villagers find the axes that outsiders use to orient information on Lwandile insufficient and indeed, collectivist culture has been associated with "high-context communication" where people ascribe meaning by reference to local context more than to abstractions [6]. The FRCC's workshop integrated natural and cultural heritage and development topics more holistically than if structured according to Western, urbanized, catagorisations and the narratives used by representatives of the national/provincial and traditional institutions differed. For instance, abstractions about land legislation, which in practical application derive from traditional mechanisms, incited contentions that they did not convey the meanings that entwine identity with a physical setting in which kin have resided for generations.

Lwandile's topological isolation and a daily-life spent outdoors means villagers are not anonymous and from birth to burial, and beyond, their identity becomes etched into the land. Even villagers migrating for work often return to Lwandile to retire or are buried in their umzi so ancestors' graves are close to home (e.g. $40 \%$ of the Sithelo clan reside in cities far away, but will be buried locally). Xhosa names are indexical to place, both in meaning (e.g. Hlathinkhulu means 'of big forest') and as a located symbol. The language carries in the open-air and I began to acutely associate name sounds with umzis, for instance by hearing a grand-parent's frequent call to a child for an errand. The relevance of origin explains the Facebook Group: Khanizi thuthe bantu! where 2453 people have joined to write and discuss Xhosa, Zulu or Tswana clan names "so that we may all know where we come from". Names encode 
social relationships and ancestry symbolically and syntactically: a last name may be an ancestor's first name and first names are often phrases that tell a family story (e.g. Xolile: "thank for this long waited child"). This language morphology may help those villagers who can recite ancestors' names across generations and contribute to many people's eagerness to explain the meaning of their names.

As one middle-aged woman explained, the provincial representative's statements about ownership documents, such as "This is your land .... here is your title and here is your land and heritage", do not tell of the way name and place bond a community through practice. This resonates with our experience of the need to link digital resources to the topological, social and metaphysical infrastructures of land in Indigenous Australian culture to contextualise information at "right spot, right time" and the difficulty of doing so when the nature of the semantic inscription in landscape is so difficult for a designer to discern; for example, in a terrain of similar rondavals, merging into similar hills rolling in, all directions, to the horizon. Thus, the axes that orient villagers to information may be more perceptible by accompanying them in the actions that embody them. The landscape progresses the narrative of stories, prompts recollects and indexes villagers' practices. H. Sithelo chose to be interviewed under the tree in front of the Great Place (Fig. 1d) which commands a panoramic view and gestures across the hills of Lwandile when reminiscing sending a messenger on a horse; Thulani animated stories of his youth by indicating a forest; and, Bulelwa took a photo of the guava tree her brother planted. The furniture of rural life shaping interactions in conversations along roads and paths, across fences and at meeting places is as much outdoors (hills, water sources, farm animals, football field) as it is built (homes, Spazas, churches, shebeens). The features of, and material used, in storytelling join to expectations which seem bound to community, for instance, people were in $90 \%$ of Thulanis' photos of his construction work, domestic and village life.

When participants joined in songs several times a day at the workshop there was a sense of solidarity, but in contrast to national representatives' emphasis on a concept of African identity, villagers stressed being Khonjwayo. Such identification affords security (e.g. only gardens along the main road are gated and doors are locked only on departure for distant travel) and involves proximity (e.g. six Sithelos prefer to sleep in only one of the dwellings in the umzi). It also requires access, for example the Sithelo clan has several proximal umzi but the incumbent Headman always lives on the highest hill where villagers' can congregate for songs before work or for meetings (e.g. with the Councilor). Simultaneously, creating and expressing belonging separates villagers' intimate locale from more contemporary structures. For example, people were at ease telling me they went to the clinic or one of Lwandile's churches but not that they consulted any of Lwandile's many sangomas, who provide traditional herbal medicine and spiritual counselling. I also encountered signals for privacy around death, a fairly frequent occurrence, for instance the only time I felt unwelcome in the Sithelo's flat was on interrupting a meeting about a death and Thulani was emphatic that his photos of funerals (comprising $9 \%$ of his collection) must not be published. Boundaries between modern and traditional institutions (e.g. [5]) are re-interpreted in language and Internet use. Villagers prefer the rhythm, melody and richness of Xhosa's multi-syllabic words but may mix English into speech, particularly for numbers, institutions, biblical words and to translate their names (e.g. Thulani calls himself Patrick to outsiders) and apply that to their use of the internet (e.g. searching 
web-based resources on HIV in English). The use of social networking sites also exhibits a boundary between the local and the remote, consider how Thulani uses Facebook to link to people overseas, few of whom he knows, but not to Xhosa 'friends'; in contrast with rural users in the West [8].

\subsection{Participation in Information Contributes to Collectivity}

Design activities need to be compatible with those features of primary orality and performance that construct traditional identity. For instance, they should not threaten social structures in the way people in Lwandile, and on the remote African island of Ibo, attribute to American movies even though few people have access to television.

Customs suggest that villagers appreciate that knowledge is distributed across human repositories in oral traditions and participation in discourse contributes to collectivity. Headmen enact decisions about collectively owned resources based on prolonged, transparent debate to achieve consensus and Thulani believes that resolution emerges by listening to multiple perspectives not by overt coercion. Perhaps this view of consensus explains why Thulani associated the FRCC with a distant US, politically- oriented "I bet I can find 1000,000 people who ..." group. Traditions where leaders deferred to the general opinion of a court seem to be echoed in the ways meetings involving the Headman are 'chaired' by whoever raises an issue and mobilize experience spanning different views. For example, $20 \%$ of the 50 men attending the Mngciebe community meeting spoke and meetings of the FRCC, or between Thulani and the NGO, or at the workshop involved disparate perspectives and ideologies. The time spent listening and the significance of a presenter's role in cohesion is illustrated by the content of Thulani and Sixolile's photos, where $83 \%$ at the school opening, $53 \%$ at funerals and $48 \%$ at the kings party were of speakers or singers. Participation in discourse may involve 'handling' content within ritualised genres with defined linguistic structure or gesture, such as protocols of thanks or greetings. This handling provides significance to items and relations and shapes the context of consensus. For instance, patronage and "friendship made by speaking" is a rhetoric that shapes significance as shown when Thulani drew the Education Minister into a photo narrative. The Principal of Lwandile School asked Thulani and I to take photos of the poorly resourced and cramped classrooms in which staff "diligently" teach. Later at the opening of a pristine, new school Thulani took many photos of Chief Gwadiso and the Minister and, when they were encircled by apparatchiks, showed his photos of them and, then, of the decrepit school.

In designing for local information sharing in Lwandile we need to consider the role of etiquettes of ingratiation and participation in information structure and be wary about a structure that forces a singular flow of linear narrative, for example bound to the unidirectional timeline of video or a chronology of photos. This often happens in digital storytelling projects and is vital for marginalized voices to speak into Western markets (e.g. via YouTube) [2]) but not best suited to local information use where building rapport is prioritised over efficiency in information economies. While villagers' narratives often had a conventional story arc, for instance in re-telling the Sithelo's genology, building consensus from different viewpoints around a theme requires connections in various directions from disparate parts. Various Web 2.0 productivity tools enable people to annotate media content, such as by adding their own 
narration to on-line image slide shows, often providing diverging commentaries in the multi-vocal market of the Web, with its provenance of text and indirect orality. However, if operating within a group of interdependent voices, the orthogonal relationships interrupting a linear story may support consensus and common goals. Villagers often said, with pride, "we share what we have" and that neighbourly assistance was "what it means to be African ... it's our identity", sometimes refering to Ubuntu' which translates to "the being human of a human being is noticed through his or her being human through human beings" [14]. Villagers exchanged effort in many ways and survive, like rural communities globally, by co-operation however their reiteration of reciprocity as uniquely African suggests that they do not recognise interdependence as a Western trait. Rather they link autonomy to democracy, which they also attribute to social dysfunction. Pursuing unanimity through prolonged discussion may be a consequence of oral narrative's inherent malleability to history and politics and unify the community to maintain elder and patriarchal authority. Placing a unitary authoritarial narrative over information may disenfranchise the villagers, for example consider how the version of Sithelo genealogy within Lwandile differs markedly from that recited by Chief Gwadiso's emissary. We might expect convergence to a linear story while a traditional leader acts in the community's interests, much like years ago leaders stabilized tribal territories by bestowing economic protection in return for allegiance. Today the community supports a leader's success if it profits (e.g. Thulani's construction business provides jobs) and affirms community identity (e.g. Thulani's logo for the FRCC is four hands shaking above his own building tools) but withdraws support from a leader who prioritizes his individuality (e.g. villagers describe Chief Gwadiso as "too greedy").

\subsection{Repetition to Create Consensus and Empathy}

Translating a network of information to create tools for sharing presents difficulties for designers who may not necessarily recognize the rules that signify an item exists at an intersection. For example, an outsider might not realize, conceptually, that there are commonalities or interdependencies in information items. However, in codifying interdependencies across villagers' perspectives we note the role of repetition in group cohesion [16] and managing oral and performed interaction. Repetition may be a defining trait of oral traditions [13] to enable learning by rehearsal to yield collective memory (e.g. workshop participants were eager to show that they memorised dates, Thulani commented that it is usual to remember many phone numbers). Repetition shares context across generations by re-embodying the past through the particular phrasings of speech, actions or interactions with land, such as in retaining TK when Elders demonstrate fire practice to younger clan members. This longitudinal, or diachronic, repetition can involve people in meaning by connecting the immediate moment with prior occasions, setting the scene or emphasising part of a scene [16]. Repeating phrases and gestures across time enabled me to establish trust by authenticating significant items in momentary interactions. But repetition may also transmit core concepts that are inaccessible to rational logic; consider being invited to join an intimate circle of women on Ibo dancing to drum beats in a darkened ruin. The women shared a pattern unfamiliar to me; yet, in conforming to the repetitious movement, there was some 'primal' connection in sensory experience. Dance lacks 
the linearity of stories, and is life rather than a depiction, often mixed with spirituality, for instance African and indigenous Australian ceremonial dancers experience a transcendent reality to connect with ancestry. It appears Lwandile villagers are aware of such collective embodiment of information. For instance, the statement about heritage: "people who are very, very eager to learn more, very eager to do it with whatever they have" did not appear to be a mistranslation but to refer to embodying information through actions.

The hooks in Lwandile's social fields to which we tether design directions need to account for gendered participation in information and the different roles of repetition in managing oral and performed interaction. For example, only men made speeches at the Mngciebe meeting of 50 men and 12 women (Fig. 1f) and, only males asked questions or orated amongst the 24 male and 46 females in the main workshop sessions, while females prepared dinner or listened and took notes. At meetings in Lwandile in mixed groups people listen quietly until a speaker finishes before contributing (Fig 1f), and men tended to stand out vocally often using synchronic repetition to enhance dramatic qualities, for instance at the Mngciebe meeting men frequently gesticulated to parts of the land in similar ways when negotiating the price they should charge outsiders for sand. In contrast, women Lwandile are inclined to conform and to harmonize in their daily songs. We also observe a tendency for speech to overlap in Quimana women's conversation on Ibo with their increased involvement in discussions about the changes the island has undergone, whereas men on Ibo always spoke asynchronously. Perhaps these nuances reflect the need to manage interaction differently, for example in Lwandile women talk in clusters often sitting on the ground behind the Great Place or during their daily tasks (e.g. collecting water, washing laundry, visiting the clinic) while men tended to talk sit in small lines or stand overlooking the under a tree in front of the Great Place (Fig. 1 b) \& d). Hardy has started applying features of synchronous speech in designing technologies inspired by her observations that Indigenous women perceive finishing or inserting a phrase in another's sentence as empathic rather than as interruptive [4].

\section{Conclusion}

We do not imagine that the properties of indexicality that we have identified in villagers' priorities and oral and performed practices are complete, unique to African rural living or are necessarily the most primary for collectivity in rural communities. Instead, we propose they can inspire concrete ways for local social structures to impact on activities to design systems of information organization, by allowing designer's to handle items important to local communication that may be less obvious in the market of symbols, concepts and structural forms that sustain communications tuned by a heritage of indirect orality and text. We suggest our handling can help us to develop an appropriate sensitivity to associations between the identity of the user and the meaning of collectivity inscribed in unbuilt physical settings. For example, our current activities to involve villagers in designing technologies respond to relationships between physical settings, group cohesion, collective memory and consensus-building communication practices, such as repetition. 


\section{References}

1. Attewell, P.: Ethnomethodology Since Garfinkel. Theory and Society 1179(2), 179-210 (1974)

2. Bidwell, N.J., Standley, P.M., George, T., Steffensen, V.: The Landscape's Apprentice: Lessons for Design from Grounding Documentary. In: Proc. Designing Interactive Systems DIS 2008, Cape Town (2008)

3. Bourdieu, P.: Language and Symbolic Power. Harvard University Press (1991)

4. Browning, D., Bidwell, N.J., Hardy, D., Standley, P.: Rural Encounters: Cultural Translations Through Video. In: Proc. OZCHI 2008, pp. 148-155 (2008)

5. Byrne, E \& Sahay, S (2006) Activity theory as an analytical tool: a case study of IS development for an anti-retroviral treatment clinic in South Africa. Proc. South African institute of computer scientists and information technologists. ACM Int. Conf. Proc. (24) 7

6. Erez, M. and Earley, P.C. (1993), Culture, Self-identity, and Work, Oxford

7. Garfinkel, H.: Studies in Ethnomethodology. Prentice Hall, Englewood Cliffs (1967)

8. Gilbert, E., Karahalios, K., Sandvig, C.: The Network in the Garden: An Empirical Analysis of Social Media in Rural Live. In: Proc. CHI 2008, vol. 12, pp. 1603-1612 (2008)

9. Heeks, R.: Information Systems \& Developing Countries: Failure, Success, \& Local Improvisations. The Information Society 18, 101-112 (2002)

10. Kim, U., Yang, G., Hwang, K.: Indigenous and Cultural Psychology. Springer, Heidelberg (2006)

11. Marsden, G., Maunder, A., Parker, M.: People are people, but technology is not technology. Phil. Trans. R. Soc. A (2008)

12. Ong, W.: Orality and literacy: The technologizing of the word. Methuen, London (1982)

13. Rosenberg, B.A.: The Complexity of Oral Tradition. Oral Tradition 2, 73-90 (1987)

14. Shutte, A.: Philosophy for Africa. Marquette University Press, Milwaukee (1993)

15. Suchman, L.: Located Accountabilities in Technology Production. Scandinavian J. of Information Systems Archive 2(14), 91-105 (2003)

16. Tannen: Talking voices: repetition, dialog, and images in conversational discourse. Cambridge University Press, Cambridge (1989)

17. Tucker, W., Blake, E.: The Role of Outcome Mapping in Developing a Rural Telemedicine System. In: Cunningham, P., Cunningham, M. (eds.) Proc. IST-Africa 2008, IIMC Int. Information Management Corp. (2008)

18. http://www. unesco.org/culture/

19. Walker, K., Underwood, J., M-Waema, T., Dunckley, L., et al.: A Resource Kit for Participatory Socio-Technical Design in Rural Kenya. In: Proc. CHI 2008, pp. 2709-2714. ACM Pr., New York (2008)

20. Winschiers, H., Fendler, J.: Assumptions considered harmful. In: Aykin, N. (ed.) HCII 2007. LNCS, vol. 4559, pp. 452-461. Springer, Heidelberg (2007) 